\title{
Fabricación de piezas de fundición con grafito esferoidal en molde metálico(*)
}

\author{
A. Urrestarazu*, J. Sertucha**, R. Suárez** e I. Álvarez-Ilzarbe***
}

\begin{abstract}
Resumen
En este trabajo se estudia el empleo de moldes metálicos o permanentes para la fabricación de piezas de fundición esferoidal con elevados requerimientos funcionales y se analizan sus propiedades, comparándolas con piezas obtenidas utilizando moldes de arena de sílice, de acuerdo con las metodologías más habituales para este tipo de procesos. La elevada velocidad de solidificación y el posterior enfriamiento rápido de la austenita formada en estado sólido se erigen como los principales factores diferenciadores que originan las modificaciones estructurales detectadas en las piezas. Las propiedades físicas, mecánicas y microestructurales obtenidas directamente sobre pieza son destacables debido, entre otros aspectos, al gran número de esferoides grafíticos obtenidos en las piezas. Se discuten también las ventajas e inconvenientes encontrados en esta metodología de producción que emplea moldes fabricados con una aleación metálica específica.
\end{abstract}

\section{Ductile iron castings fabricated using metallic moulds}

\begin{abstract}
The features and suitability of high requirements ductile iron castings production using metallic moulds have been studied in the present work. The structural and mechanical properties of the produced castings have been analysed and compared to the corresponding ones but fabricated using green sand moulds according to a conventional production process. The higher cooling rate in the metallic moulds is the main cause for the appearance of the detected structural changes in castings. The mechanical and microstructural properties obtained directly on castings are remarkable due to the higher nodule count among other factors. Finally, the benefits and inconveniences found in this kind of production methodology using metallic moulds are also discussed.
\end{abstract}

Keywords

Ductile iron; Metallic moulds; Structural characteristics; Mechanical properties.

\section{INTRODUCCIÓN}

La fabricación de piezas de fundición de hierro está orientada fundamentalmente a la obtención de materiales metálicos económicamente competitivos y con propiedades ajustadas a la funcionalidad de los componentes diseñados. Dentro del sector de automoción, parte de los esfuerzos de investigación actuales se orientan hacia la obtención de fundiciones grafíticas con propiedades optimizadas ${ }^{[1-3]}$. El objetivo de estos "nuevos materiales de fundición" se centra en ofrecer una alternativa más económica a la utilización de los aceros u otras aleaciones especiales para la fabricación de piezas de altas exigencias ${ }^{[1]}$. En el campo de las fundiciones de hierro con grafito precipitado, la fundición esferoidal constituye uno de los materiales con más recorrido desde su descubrimiento en la década de los 50. En comparación con la fundición laminar o gris, la formación y posterior crecimiento de los grafitos bajo la forma esferoidal supone mejoras considerables en la carga de rotura, límite elástico y, especialmente, en el alargamiento y la tenacidad del material. Una combinación adecuada de estas propiedades físicas supone la obtención de materiales con un extenso campo de aplicación tecnológica.

Adicionalmente, la generación de esferoides grafíticos de forma masiva en el seno de la matriz metálica tiene consecuencias aún más interesantes. En

(•) Trabajo recibido el día 20 de septiembre 2012 y aceptado en su forma final el día 31 de enero de 2013.

* Greyco, S.L.U., La Agüera s/n, E-39409 San Felices de Buelna (Cantabria), E-mail: a.urrestarazu@greyco.es

** Centro de Investigación Metalúrgica AZTERLAN, Ingeniería y Procesos de Fundición, Aliendalde Auzunea n 6 , E-48200 Durango (Bizkaia). E-mail: jsertucha@azterlan.es

${ }^{* * *}$ Frenos Iruña, S.A.L., Polígono Industrial Comarca 2, calle E n 9, E-31191 Barbatain (Navarra), E-mail: ignacio.alvarez@irunabrakes.es 
estas circunstancias, se favorece la difusión de los átomos de carbono ${ }^{[4]}$ hacia los numerosos esferoides disponibles durante el período de enfriamiento de la fase austenítica. En consecuencia, se obtienen las condiciones adecuadas para la formación y posterior crecimiento de la ferrita durante la transformación sólido-sólido ${ }^{[5}$ y 6$]$. Esta fase estructural confiere al material un elevado grado de ductilidad y resistencia al impacto, exceptuando aquellos casos en los que los contenidos de silicio y/o fósforo en la aleación son elevados ${ }^{[7}$ y 8$]$.

Por otra parte, es bien conocida la influencia de las condiciones de enfriamiento sobre las características estructurales y, por tanto, sobre las propiedades físicas, mecánicas y microestructurales de las fundiciones de hierro con grafito esferoidal ${ }^{[6,9-11]}$. En la mayoría de los procesos de fabricación actuales se utilizan moldes configurados con mezclas que contienen arena de sílice como constituyente mayoritario. Este material refractario se caracteriza por poseer una conductividad térmica comparativamente baja $^{[12]}$, lo que limita en gran medida la velocidad de enfriamiento de la aleación colada en el interior de este tipo de molde. Sin embargo, se trata de un material abundante, con gran variedad de formas, tamaños y distribuciones de grano y de fácil aplicación en los procesos de producción.

Una metodología alternativa para la fabricación de los moldes es la propia fundición de hierro. Aunque la utilización de moldes metálicos o "permanentes" en la fabricación de piezas de fundición coladas por gravedad se documenta en la bibliografía ${ }^{[13-15]}$, se trata de una metodología minoritaria ${ }^{[15}$ y 16] (aproximadamente el 7\% del total de piezas de fundición fabricadas en Europa), escasamente estudiada y con amplio recorrido para su desarrollo debido a su singularidad. Esta técnica puede emplearse para la fabricación de piezas de fundición para el sector de automoción ${ }^{[17]}$, componentes hidráulicos, moldes metálicos para la industria del vidrio, tubos centrifugados, etc. ${ }^{[15]}$. El empleo de moldes metálicos incrementa la velocidad de solidificación y posterior enfriamiento del material, generando cambios importantes en las estructuras obtenidas en el estado bruto de colada ${ }^{[13}$ y 16]. En el presente trabajo se estudian comparativamente las implicaciones derivadas de utilizar moldes de arena de sílice o metá- licos para fabricar piezas de fundición nodular con altos requerimientos y destinadas a diferentes sectores industriales. Por otro lado, se determinan las ventajas e inconvenientes de utilizar moldes permanentes en un proceso productivo.

\section{PARTE EXPERIMENTAL}

El proceso de fusión de los materiales se realizó en un horno rotativo con capacidad para $5.200 \mathrm{~kg}$. Las cargas metálicas utilizadas estuvieron constituidas por el $70 \%$ de lingote de alto carbono, el $25 \%$ de acero procedente del sector de construcción y el $5 \%$ de retornos. Tras la fusión de estas cargas, el metal resultante se trasladó a tres hornos de inducción $(750 \mathrm{~Hz}, 400 \mathrm{~kW})$, cada uno con $1.600 \mathrm{~kg}$ de capacidad, con el fin de ajustar los contenidos de carbono y silicio (\% en peso), empleando grafito: $\mathrm{C} \geq 99$ y $\mathrm{FeSi}: \mathrm{Si}=74,6 ; \mathrm{Al}=0,8 ; \mathrm{Fe}=24,6$ y elevar la temperatura del metal base hasta los $1.460-1.490^{\circ} \mathrm{C}$. La tabla I muestra los intervalos de composición química obtenidos durante la preparación del metal base.

Los tratamientos de esferoidización del metal base se efectuaron trasvasando $70 \mathrm{~kg}$ desde los hornos eléctricos a una cuchara de tratamiento con $90 \mathrm{~kg}$ de capacidad máxima, dotada con una cámara de reacción en su parte inferior y un sifón para la salida del metal. Antes de llevar a cabo el trasvase del metal desde los hornos, en el interior de la cámara de reacción se introdujeron en este orden: $0,60 \mathrm{~kg}$ de la aleación $\mathrm{FeSiMg} 621$ (\% en peso: $\mathrm{Si}=44,1 ; \mathrm{Mg}=6,8$; $\mathrm{Ca}=2,2 ; \mathrm{Al}=0,6$; tierras raras $=1,2 ; \mathrm{Fe}=45,1 \mathrm{y}$ granulometría $2-10 \mathrm{~mm}), 0,11 \mathrm{~kg}$ de un inoculante comercial (\% en peso: $\mathrm{Si}=64,3 ; \mathrm{Ca}=1,3 ; \mathrm{Al}=0,9$; $\mathrm{Ba}=9,3 ; \mathrm{Fe}=24,2$ y granulometría $0,5-3 \mathrm{~mm}$ ) y recortes de acero de estampación como material cubriente. El vertido del metal procedente del horno de inducción se realizó dirigiendo la vena hacia el lado opuesto al ocupado por la cámara de reacción en el fondo de la cuchara de tratamiento. El control del peso de metal trasvasado se efectuó con ayuda de un dinamómetro situado en la parte superior de la cuchara.

Tras finalizar la reacción de tratamiento con magnesio, el metal se desescorió convenientemente y se

Tabla I. Intervalos de composición química en los metales base ( $\%$ en peso)

Table I. Chemical composition ranges in the base melts (wt.\%)

\begin{tabular}{ccccccc}
\hline $\mathbf{C}$ & $\mathbf{S i}$ & $\mathbf{M n}$ & $\mathbf{P}$ & $\mathbf{S}$ & $\mathbf{C u}$ & $\mathbf{C r}$ \\
\hline $3,83-3,96$ & $1,81-2,05$ & $0,68-0,74$ & $0,035-0,068$ & $0,016-0,024$ & $0,07-0,15$ & $0,01-0,06$ \\
\hline
\end{tabular}


trasladó a una cuchara de colada con capacidad para $80 \mathrm{~kg}$ y dotada con sifón para la salida del metal (Fig. 1). La finalidad de este dispositivo es evitar la introducción de escorias en el interior de los moldes durante la colada de éstos. Ocasionalmente, el metal contenido en las cucharas de tratamiento y colada se desescorió con este mismo fin. La colada de los moldes se efectuó manualmente y a través del mencionado sifón, garantizando que la copa de colada se mantuviera llena durante todo el proceso de llenado de los moldes. Se realizó una post-inoculación del metal durante su trasvase desde la cuchara de tratamiento a la de colada, adicionando en vena el 0,20\% de un inoculante comercial (\% en peso: $\mathrm{Si}=73,5$; $\mathrm{Ca}=1,7 ; \mathrm{Al}=1,0 ; \mathrm{Bi}=0,9 ; \mathrm{Fe}=22,9$ y granulometría 0,2 - 0,7 mm). En la tabla II se incluyen los intervalos de composición química obtenidos en el metal tratado con FeSiMg.

Los moldes permanentes se fabricaron mecanizando un bruto de fundición, es decir, una pieza con forma de prisma rectangular colada previamente en un molde preparado para este efecto, la cual contiene cuatro tubos de acero en su interior para permitir su refrigeración con agua. El material utilizado para preparar este bruto es fundición con grafito laminar perteneciente a la calidad EN-GJL-200 (según norma EN 1561). Tras las operaciones de mecanizado y posterior ajuste, los moldes se revistieron internamente con una capa de pintura refractaria y se montaron en un carrusel con capacidad para doce moldes, cada uno de ellos dotado con un sistema independiente de refrigeración interna por agua. En cada giro del carrusel, un sistema de quemadores alimentados con acetileno se encargó de depositar una capa de polvo de carbono sobre la pintura refractaria, la cual cubrió la cara interna de los moldes metálicos. Tras la colada, los restos de esta capa se eliminaron con ayuda de un cepillado y posterior soplado del molde. Al finalizar esta operación, se aplicó una nueva capa antes de efectuar la siguiente colada. El control de la temperatura de los moldes metálicos se realizó manualmente.

Los moldes de arena de sílice se fabricaron con ayuda de una línea de moldeo vertical de alta presión
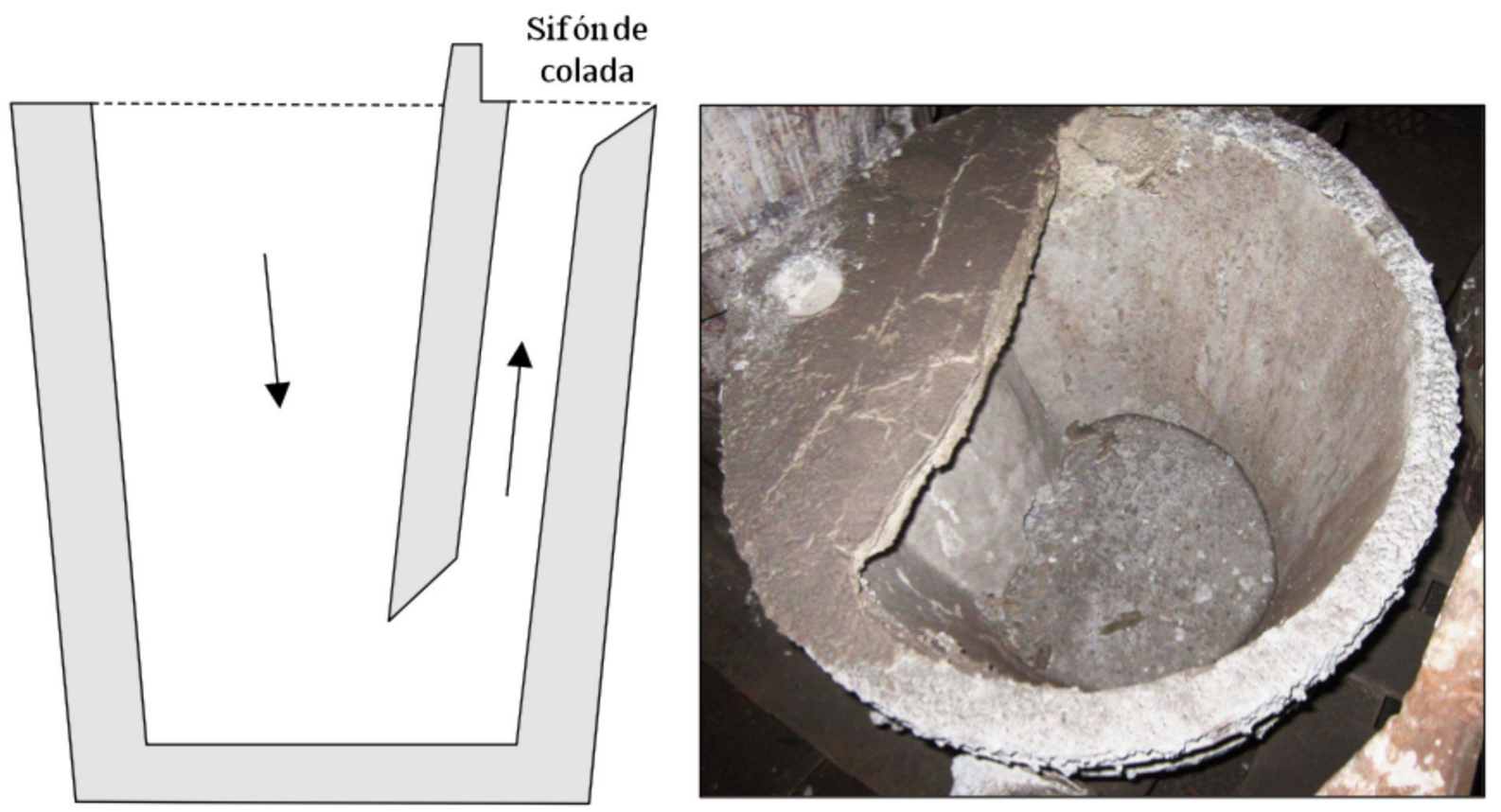

Figura 1. Cuchara de tetera utilizada para colar los moldes metálicos.

Figure 1. Siphon type ladle used when casting the permanent moulds.

Tabla II. Intervalos de composición química en los metales tratados con FeSiMg (\% en peso)

Table II. Chemical composition ranges in the Mg-treated melts (wt.\%)

\begin{tabular}{ccccccc}
\hline $\mathbf{C}$ & $\mathbf{S i}$ & $\mathbf{M n}$ & $\mathbf{P}$ & $\mathbf{S}$ & $\mathbf{M g}$ & $\mathbf{C u}$ \\
\hline $3,72-3,81$ & $2,55-2,67$ & $0,66-0,74$ & $0,024-0,041$ & $0,009-0,016$ & $0,026-0,038$ & $0,09-0,14$ \\
\hline
\end{tabular}


y mezclas constituidas por: $80,8 \%$ de arena de sílice reutilizada, 9,3\% de bentonita sódica activada, 4,5\% de material carbonoso, $3,6 \%$ de agua y $1,8 \%$ de arena nueva de sílice. Las mezclas se enviaron a la máquina de moldeo con una compactabilidad de 38 - 41\%. En este caso, el metal base se preparó introduciendo las cargas metálicas descritas anteriormente en un horno de inducción $(250 \mathrm{~Hz}, 500 \mathrm{~kW})$ con capacidad para 10 t. La composición del metal base se ajustó a los valores indicados en la tabla I. Los tratamientos de nodulización se llevaron a cabo utilizando una cuchara con capacidad para $1.250 \mathrm{~kg}$, de acuerdo con la metodología tundish cover. Antes de verter el metal en su interior, en la cámara de reacción de esta cuchara se introdujeron $15 \mathrm{~kg}$ de la ferroaleación FeSiMg 522 (\% en peso: $\mathrm{Si}=45,4 ; \mathrm{Mg}=5,6$; $\mathrm{Ca}=1,6 ; \mathrm{Ce}=0,8$; tierras raras $=1,9 ; \mathrm{Fe}=46,6$ y granulometría $2-12 \mathrm{~mm}$ ) con ayuda de un tubo direccionador. Como material cubriente, se emplearon recortes de acero (tamaño $5-15 \mathrm{~mm}$ ) procedentes de procesos de estampación. El vertido del metal base a la cuchara de tratamiento se realizó cuando la temperatura de éste era $1.490-1.500{ }^{\circ} \mathrm{C}$. Una vez finalizada la reacción, el metal se desescorió en la propia cuchara y se trasladó a una unidad de colada presurizada con capacidad para $7 \mathrm{t}$ y localizada junto a la línea de moldeo vertical de alta presión. El proceso de inoculación del metal de colada se llevó a cabo adicionando en vena el 0,20\% de un inoculante comercial (\% en peso: $\mathrm{Si}=68,1 ; \mathrm{Ca}=1,7$; $\mathrm{Al}=0,9 ; \mathrm{Bi}=0,5 ; \mathrm{Ba}=0,4 ;$ tierras raras $=0,4 ; \mathrm{Fe}=28,0$ y granulometría 0,2-0,5 mm). La composición química del metal de colada correspondió a los intervalos mostrados en la tabla II.

Las piezas utilizadas para llevar a cabo el presente estudio son: un componente del freno empleado en los aerogeneradores (pinza de freno $G$ ), una pieza perteneciente al sistema de freno de un vehículo eléctrico (pinza de freno E) y una mordaza de sujeción para raíles ferroviarios (mordaza). La masa de la pinza de freno $G$ es $7,2 \mathrm{~kg}$, mostrando secciones entre 5 y $43 \mathrm{~mm}$. La pinza de freno $\mathrm{E}$ tiene una masa de $0,71 \mathrm{~kg}$ y cuenta con secciones de $8-42 \mathrm{~mm}$. En el caso de la mordaza, el peso es $0,35 \mathrm{~kg}$ y las secciones varían entre 5 y $12 \mathrm{~mm}$. De este modo, ha sido posible evaluar el efecto de las diferentes velocidades de enfriamiento en un mismo tipo de pieza fabricado en moldes metálicos y de arena.

Las piezas fabricadas tanto en moldes metálicos como en los fabricados con mezclas de arena de sílice corresponden a las pinzas de freno $\mathrm{G}$ y $\mathrm{E}$. En el caso de la pinza $\mathrm{G}$, los moldes contenían dos piezas, mientras que este número aumentó a ocho para la pinza E. En los moldes de arena, fue necesario incluir sistemas de alimentación con el fin de evitar la formación de defectos de contracción (rechupes y/o microrrechupes). Estos dispositivos de alimentación no fueron necesarios a la hora de fabricar la pinza de freno $\mathrm{G}$ utilizando los moldes metálicos. En el caso de la mordaza, se utilizaron únicamente moldes metálicos que contenían quince piezas y tampoco fue necesario emplear mazarotas. Los intervalos de temperatura durante la colada fueron: $1.330-1.360^{\circ} \mathrm{C}$ para las piezas fabricadas utilizando moldes metálicos y $1.380-1.410^{\circ} \mathrm{C}$ para las pinzas obtenidas a partir de los moldes de arena. Las temperaturas de coquilla fueron: $210-250^{\circ} \mathrm{C}$ para la pinza de freno $\mathrm{G}, 170-210^{\circ} \mathrm{C}$ para la pinza de freno E y $200-250^{\circ} \mathrm{C}$ para la mordaza. Tras su fabricación, las piezas se desmoldearon y, sólo en el caso de las pinzas de freno E y las mordazas, se sometieron a un tratamiento térmico de ferritización con objeto de eliminar los carburos detectados en determinadas secciones estrechas (tres piezas de cada tipo se mantuvieron en estado bruto de colada con el fin de realizar los correspondientes estudios metalográficos y, en el caso de la pinza E, la determinación de las propiedades mecánicas). El tratamiento térmico aplicado consistió en un calentamiento hasta $950^{\circ} \mathrm{C}$, un período de permanencia a $930-950^{\circ} \mathrm{C}$ durante 60 min y un enfriamiento a $4,5^{\circ} \mathrm{C} / \mathrm{min}$ hasta alcanzar los $450^{\circ} \mathrm{C}$. Tras el granallado final, todas las piezas se inspeccionaron por fluoroscopía de rayos X con el fin de detectar la presencia de porosidades internas. Posteriormente, los materiales de estas piezas se sometieron a un estudio metalográfico para determinar el índice de esferoidización (IE), la densidad de nódulos $(\mathrm{N})$ y la composición de la matriz metálica en diferentes secciones. Los valores de estos parámetros se obtuvieron analizando cinco campos de observación diferentes en cada muestra y comparándolos con

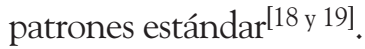

Los valores de carga de rotura (R), límite elástico (LE) y alargamiento (A) se determinaron ensayando probetas de tracción (según norma EN 1563) mecanizadas directamente sobre las pinzas de freno $G$ y $E$ (moldes de arena y metálico) y las mordazas (molde metálico). La dureza Brinell se midió en las secciones de mayor tamaño pertenecientes a las pinzas de freno G y E, empleando una esfera de diámetro $10 \mathrm{~mm}$ y una carga de $3.000 \mathrm{~kg}$. Para llevar a cabo estos ensayos físicos, se seleccionaron tres piezas de cada tipo. En las mordazas de sujeción, los ensayos mecánicos se realizaron únicamente sobre piezas sometidas al tratamiento térmico de ferritización, debido a la presencia de pequeños carburos repartidos por la matriz metálica. Para determinar las propiedades mecánicas en las pinzas de freno E, se emplearon tanto piezas en bruto de colada como aquéllas sometidas al tratamiento térmico. Este hecho fue posible puesto que los carburos detectados se encontraron únicamente en algunas secciones inferiores a $11 \mathrm{~mm}$. En el caso de las pinzas de freno $G$, los materiales se ensayaron en estado bruto de colada, debido a la ausencia sistemática de carburos en la matriz metálica. Las 
dimensiones de estas probetas dependieron de la zona de la pieza de donde fueron obtenidas.

Por otra parte, un grupo constituido por dos mil pinzas de freno $G$ fabricadas con los moldes de arena y otras tantas fabricadas con los moldes metálicos (todas ellas en el estado bruto de colada) se emplearon para llevar a cabo un estudio comparativo de maquinabilidad. Otro grupo formado por diez pinzas E, la mitad de ellas fabricadas con moldes de arena y la otra mitad con moldes metálicos (estas últimas sometidas al tratamiento térmico de ferritización), se utilizó para comparar la resistencia de estos materiales frente a la corrosión, tras la aplicación del correspondiente recubrimiento superficial en todas las piezas (zincado electrolítico y posterior bicromado). Los ensayos de corrosión se llevaron a cabo según la norma ISO 9227:2006, introduciendo las pinzas cromadas en el interior de una cámara de niebla salina durante $792 \mathrm{~h}$ a una temperatura de $33-37^{\circ} \mathrm{C}$. La disolución salina utilizada se preparó adicionando $50 \mathrm{~g}$ de $\mathrm{NaCl}$ de alta pureza en cada litro, resultando un $\mathrm{pH}=6,5-7,2$. La presión de rociado en el interior de la cámara fue de $1,00 \mathrm{~kg} / \mathrm{cm}^{2}$ y la recogida pluviométrica $1,50 \mathrm{~cm}^{3} / \mathrm{h}$. La tabla III muestra un resumen de los diferentes ensayos realizados en cada tipo de pieza.

\section{RESULTADOS Y DISCUSIÓN}

Las caracterizaciones estructurales se llevaron a cabo en una sección estrecha y otra masiva, pertenecientes a tres pinzas de freno de cada tipo ( $\mathrm{G}$ y $\mathrm{E}$ ), fabricadas tanto en moldes metálicos como en arena, y tres mordazas (todas ellas en bruto de colada). Posteriormente, el mismo número de pinzas de freno $\mathrm{E}$ y mordazas se sometieron a un tratamiento térmico de normalizado con el fin de eliminar las fases carbúricas detectadas. Las estructuras matriciales obtenidas en todas las piezas sometidas a tratamiento térmico son mayoritariamente ferríticas, contienen un máximo de 5 - 10\% de perlita y no se detectan carburos. Los resultados obtenidos a partir de los estudios metalográficos realizados sobre los materiales en bruto de colada se incluyen en la tabla IV.

El análisis comparativo de los datos contenidos en la tabla IV muestra un importante incremento en el número de esferoides grafíticos cuando el enfriamiento del material tiene lugar en el interior de los moldes metálicos. Este hecho puede comprobarse claramente al comparar los valores del parámetro $\mathrm{N}$ en las pinzas de freno $\mathrm{G}$ y $\mathrm{E}$ fabricadas utilizando moldes de arena y metálicos. En el caso de la mordaza de sujeción, se trata de una pieza de menor tamaño y con secciones más delgadas. Sin embargo, para una sección de tamaño similar, se obtienen valores similares de la densidad de nódulos grafíticos con respecto a las pinzas de freno. Este hecho revela la fuerte influencia de la velocidad de solidificación en los valores obtenidos del parámetro $\mathrm{N}$.

Otro aspecto a considerar es el contenido de ferrita observado en cada caso. Las pinzas de freno $G$ fabricadas en el molde metálico son mayoritariamente

Tabla III. Ensayos realizados sobre las piezas fabricadas en este estudio

Table III. Summary of tests performed on castings fabricated in this work

\begin{tabular}{lcccc}
\hline Pieza & Pinza de freno G & \multicolumn{2}{l}{ Pinza de freno E } & Mordaza \\
\hline Molde utilizado & Metálico y arena & Metálico & Arena & Metálico \\
Tratamiento térmico & No & Sí & No & Sí \\
Inspección de rayos X & Sí & Sí & Sí \\
Estudio metalográfico & Sí & Sí & Sí \\
Zonas inspeccionadas & 2 & 2 & 2 \\
Propiedades mecánicas & Sí & Sí & Sí \\
No de piezas & 6 & 9 & 3 \\
Zonas seleccionadas & 2 & 1 & 2 \\
Mecanizado & Sí & No & No \\
No de piezas & 4.013 & - & - \\
Cámara de niebla salina & No & Sí & No \\
No de piezas & - & 10 & - \\
\hline
\end{tabular}


ferríticas (Fig. 2) en el estado bruto de colada. Sin embargo, aquellas piezas que proceden de los moldes de arena no superan el $30-35 \%$ de esta fase en ninguna de las secciones inspeccionadas.

Teniendo en cuenta la similitud de composiciones químicas en el metal de colada (Tabla II), este comportamiento debe ser asignado principalmente a la presencia de un mayor número de nódulos grafíticos por unidad de volumen en los materiales enfriados en el molde metálico. En estos casos, la distancia entre esferoides disminuye considerablemente y se favorece la difusión eficaz de los átomos de carbono desde la austenita hacia los esferoides grafíticos durante el enfriamiento del material en el estado sólido. Es necesario tener en cuenta que, cuando se utilizan moldes permanentes, la extracción de las piezas ocurre aproximadamente $10-15 \mathrm{~s}$ después de finalizar el llenado de los moldes. En el caso de las fabricaciones efectuadas con moldes de arena, este período de tiempo supera habitualmente los $10 \mathrm{~min}$. Es decir, las aleaciones fabricadas en moldes metálicos se enfrían al aire cuando tiene lugar la transición eutectoide, mientras que los materiales colados en moldes de arena sufren esta transformación sin ser desmoldeados. A pesar de ello, la formación de ferrita está más favorecida en el caso de aquellas aleaciones con elevados valores del parámetro $\mathrm{N}$.

Cuando se analizan las características estructurales de las pinzas de freno E, la comparación entre piezas fabricadas en moldes metálicos y de arena origina resultados diferentes a los descritos para la pinza de freno $\mathrm{G}$. En este caso, la menor masa sometida a enfriamiento hace que, aun contando con valores mucho más elevados del parámetro $\mathrm{N}$, las pinzas procedentes de moldes permanentes mantengan los contenidos de perlita en el núcleo de las secciones de $43 \mathrm{~mm}$ (Fig. 3) con respecto a las piezas análogas fabricadas en moldes de arena o incluso los aumenten en las áreas de periferia y/o en el núcleo de las secciones más estrechas $(11 \mathrm{~mm})$.

Al comparar las estructuras matriciales en secciones similares de las pinzas de freno $G$ y las mordazas, todas ellas fabricadas utilizando moldes metálicos, se observa un efecto similar al descrito en el párrafo anterior. Incluso con mayores valores del parámetro $\mathrm{N}$, las mordazas muestran menores contenidos de ferrita que las pinzas (Tabla IV). Nuevamente, este hecho está relacionado con el tamaño de las piezas y la influencia que este parámetro tiene aumentando o disminuyendo las

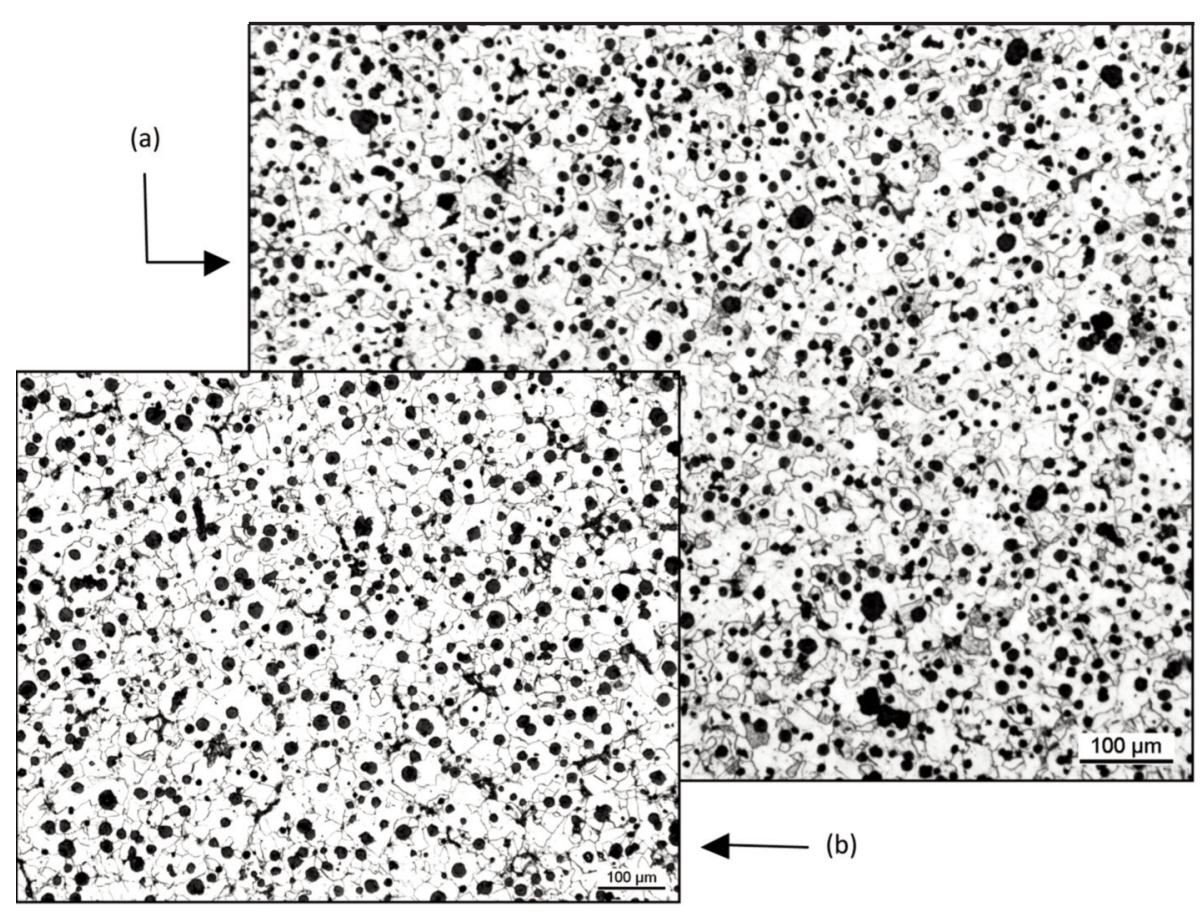

Figura 2. Morfología grafítica y estructura matricial en pinzas de freno $G$ fabricadas utilizando moldes metálicos: (a) zona de periferia en sección de $11 \mathrm{~mm}$ y $\mathrm{N}=1.361 \mathrm{~mm}^{-2}$; (b) zona núcleo en sección de $41 \mathrm{~mm}$ y $\mathrm{N}=873 \mathrm{~mm}^{-2}$.

Figure 2. Graphite morphology and structure in callipers type $G$ fabricated using metallic moulds: (a) area with $11 \mathrm{~mm}$ in section and $\mathrm{N}=1361 \mathrm{~mm}^{-2}$; (b) area with $41 \mathrm{~mm}$ in section and $\mathrm{N}=873 \mathrm{~mm}^{-2}$. 
Tabla IV. Estudio metalográfico de las piezas en estado bruto de colada Table IV. Metallographic study of the as-cast castings

Pinzas de freno G (molde metálico)

\begin{tabular}{ccccccccc}
\hline \multirow{2}{*}{$\begin{array}{c}\text { Sección } \\
(\mathbf{m m})\end{array}$} & IE & $\mathbf{N}$ & \multicolumn{3}{c}{ Estructura núcleo (\%) } & \multicolumn{2}{c}{ Estructura periferia (\%) } \\
\cline { 4 - 8 } & $(\mathbf{\%})$ & $\left(\mathbf{m m}^{-2}\right)$ & Ferrita & Perlita & Carburos & Ferrita & Perlita & Carburos \\
\hline \multirow{2}{*}{41} & $>90$ & $650-1.100$ & $85-100$ & $15-0$ & 0 & $90-100$ & $10-0$ & 0 \\
11 & $>90$ & $850-1.400$ & $90-100$ & $10-0$ & 0 & $97-100$ & $3-0$ & 0
\end{tabular}

Pinzas de freno G (molde de arena de sílice)

\begin{tabular}{ccccccccc}
\hline \multirow{2}{*}{$\begin{array}{c}\text { Sección } \\
(\mathbf{m m})\end{array}$} & $\mathrm{IE}$ & $\mathbf{N}$ & \multicolumn{2}{c}{ Estructura núcleo (\%) } & \multicolumn{2}{c}{ Estructura periferia (\%) } \\
\cline { 4 - 8 } & $\mathbf{( \% )}$ & $\left(\mathbf{m m}^{-2}\right)$ & Ferrita & Perlita & Carburos & Ferrita & Perlita & Carburos \\
\hline \multirow{2}{*}{41} & $>90$ & $180-220$ & $30-35$ & $70-65$ & 0 & $15-25$ & $85-75$ & 0 \\
11 & $>90$ & $340-450$ & $10-20$ & $90-80$ & 0 & $2-10$ & $98-90$ & 0
\end{tabular}

Pinzas de freno E (molde metálico)

\begin{tabular}{ccccccccr}
\hline \multirow{2}{*}{$\begin{array}{c}\text { Sección } \\
(\mathbf{m m})\end{array}$} & $\begin{array}{c}\text { IE } \\
(\%)\end{array}$ & $\mathbf{N}$ & \multicolumn{3}{c}{ Estructura núcleo (\%) } & \multicolumn{2}{c}{ Estructura periferia (\%) } \\
\cline { 4 - 8 } & $\left(\mathbf{m m}^{-2}\right)$ & Ferrita & Perlita & Carburos & Ferrita & Perlita & Carburos \\
\hline 43 & $>90$ & $720-980$ & $30-40$ & $70-60$ & 0 & $10-20$ & $87-70$ & $3-10$ \\
11 & $>90$ & $1.055-1.280$ & $10-20$ & $89-77$ & $1-3$ & Trazas & $80-70$ & $20-30$
\end{tabular}

Pinzas de freno $E$ (molde de arena de sílice)

\begin{tabular}{ccccccccc}
\hline \multirow{2}{*}{$\begin{array}{c}\text { Sección } \\
(\mathbf{m m})\end{array}$} & $\begin{array}{c}\text { IE } \\
(\%)\end{array}$ & $\mathbf{N}$ & \multicolumn{3}{c}{ Estructura núcleo (\%) } & \multicolumn{2}{c}{ Estructura periferia (\%) } \\
\cline { 4 - 8 } & $\left(\mathbf{m m}^{-2}\right)$ & Ferrita & Perlita & Carburos & Ferrita & Perlita & Carburos \\
\hline \multirow{2}{*}{43} & $>90$ & $280-320$ & $30-40$ & $70-60$ & 0 & $30-45$ & $70-55$ & 0 \\
11 & $>90$ & $450-570$ & $30-40$ & $70-60$ & 0 & $20-35$ & $80-65$ & 0
\end{tabular}

Mordazas (molde metálico)

\begin{tabular}{ccccccccc}
\hline \multirow{2}{*}{$\begin{array}{c}\text { Sección } \\
(\mathbf{m m})\end{array}$} & IE & $\mathbf{N}$ & \multicolumn{3}{c}{ Estructura núcleo (\%) } & \multicolumn{2}{c}{ Estructura periferia (\%) } \\
\cline { 5 - 8 } & $(\%)$ & $\left(\mathbf{m m}^{-2}\right)$ & Ferrita & Perlita & Carburos & Ferrita & Perlita & Carburos \\
\hline 11 & $>90$ & $950-1.410$ & $30-40$ & $70-60$ & 0 & $20-30$ & $80-68$ & Trazas - 2 \\
7 & $>90$ & $1.300-1.500$ & $20-25$ & $80-75$ & $0-$ Trazas & $10-15$ & $85-75$ & $5-10$ \\
\hline
\end{tabular}

velocidades de solidificación y posterior enfriamiento de la austenita cuando las piezas se desmoldean y permanecen en contacto con el aire.
Otra fase estructural detectada y que también revela la influencia de las condiciones de enfriamiento sobre las características estructurales del material son 

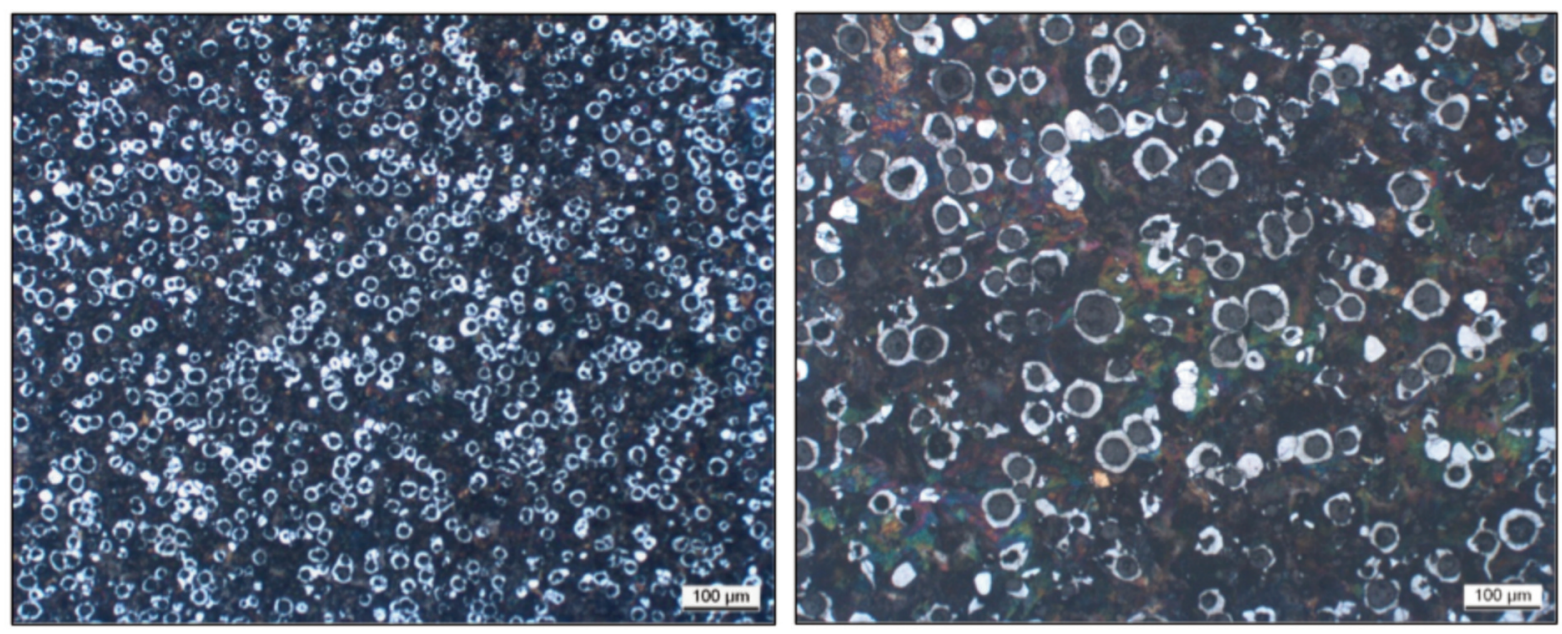

Figura 3. Estructura matricial en el núcleo (sección $43 \mathrm{~mm}$ ) de pinzas de freno $\mathrm{E}$ fabricadas utilizando moldes metálicos (izquierda) y molde de arena en verde (derecha).

Figure 3. Structures in the nucleus area (43 $\mathrm{mm}$ in section) of callipers type $E$ fabricated using metallic moulds (left) and green sand moulds (right).

los carburos de hierro. Este tipo de compuestos se forma exclusivamente durante la solidificación de las pinzas de freno E y las mordazas de sujeción, es decir, en las secciones más estrechas pertenecientes a las piezas de menor masa. Por otro lado, resulta sencillo comprobar que la mayor concentración de carburos se encuentra en las áreas de periferia correspondientes a dichas secciones. La menor masa de las piezas y el enfriamiento más rápido en las zonas de periferia (en contacto con el molde metálico refrigerado) favorecen la aparición de las fases carbúricas. Determinados autores $^{[13]}$ incluso han planteado la utilidad de los carburos formados en las áreas de periferia como medida efectiva para evitar el desgaste superficial en piezas diseñadas para determinadas aplicaciones.

Cuando se comparan secciones similares, pertenecientes a las pinzas de freno $\mathrm{E}$ y a las mordazas $(11 \mathrm{~mm})$, se observa que los contenidos de ferrita son inferiores en el primer tipo de pieza. Además, este hecho va acompañado de mayores cantidades de carburos en la matriz metálica (Tabla IV). A priori, dicho comportamiento es el contrario al que cabría esperar, teniendo en cuenta que las mordazas tienen la mitad de masa que las pinzas de freno E. Sin embargo, es necesario considerar la influencia de otros factores del proceso. El control eficaz de la temperatura de los moldes ${ }^{[14]}$ y la garantía de una inoculación efectiva en el metal de colada son también factores de gran relevancia a la hora de evitar la formación de estos carburos (Fig. 4). En el segundo caso, se trata de adicionar elementos nucleadores del grafito muy acti$\operatorname{vos}^{[20]}$ (calcio, silicio, bario, bismuto, etc.), los cuales puedan contrarrestar el efecto que ejerce la elevada velocidad de solidificación para formar carburos. En la metodología de fabricación empleada en este trabajo, se efectuaron dos inoculaciones: una de ellas en el tratamiento del metal con FeSiMg y, posteriormente, una post-inoculación en la vena de colada. A pesar de ello, no ha sido posible evitar la aparición de carburos en las secciones más críticas pertenecientes tanto a las pinzas de freno E como a las mordazas. Por ello, más que posibles diferencias en la efectividad de la inoculación, el comportamiento "anómalo"

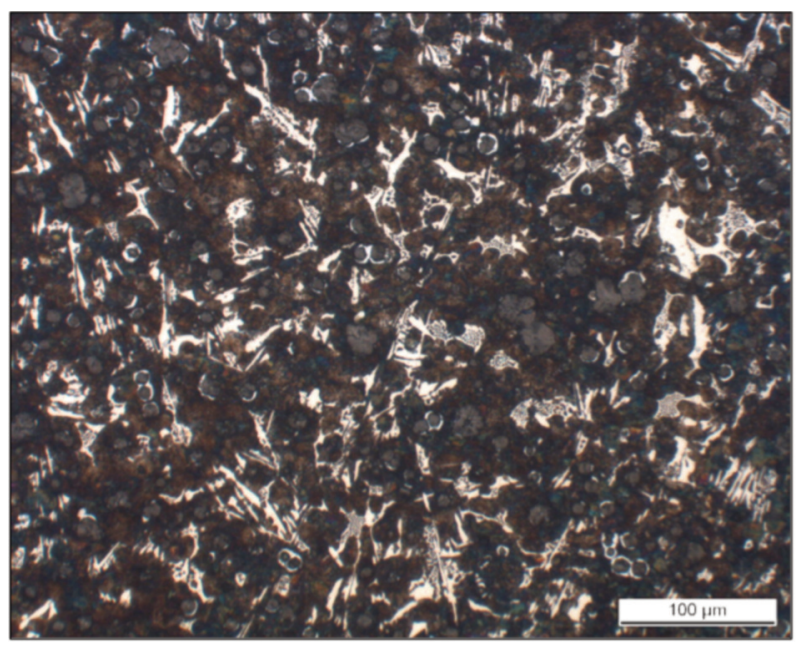

Figura 4. Carburos detectados en la estructura matricial perteneciente a la sección de $11 \mathrm{~mm}$ de una pinza $E$ fabricada en molde metálico.

Figure 4. Carbide particles found in the $11 \mathrm{~mm}$ section of a calliper type $E$ fabricated using a metallic mould. 
detectado al comparar las estructuras matriciales de las pinzas de freno $\mathrm{E}$ y las mordazas en secciones de $11 \mathrm{~mm}$ parece ser debido a las distintas temperaturas de las coquillas durante el proceso de fabricación. De este modo, las velocidades de solidificación de las mordazas se ven ralentizadas puesto que los moldes metálicos se encuentran $30-40{ }^{\circ} \mathrm{C}$ más calientes que en el caso de las pinzas de freno $\mathrm{E}$ y se obtienen estructuras con menos carburos.

Por otra parte, una adecuada inoculación del metal de colada contribuye a minimizar la formación de defectos de contracción y aumenta el número de nódulos, especialmente en las secciones más estrechas ${ }^{[16]}$. Con el fin de comprobar este último hecho, en la colada de un molde metálico, perteneciente a la pinza de freno $G$, se eliminó la post-inoculación. El estudio estructural de las dos piezas obtenidas a partir de este molde mostró una reducción del 20 - 25\% en los valores del parámetro $\mathrm{N}$ con respecto a los mostrados en la tabla IV, un ligero incremento del contenido de perlita ( $\leq 20 \%$ ) y se detectaron carburos en algunas de las secciones inferiores a $10 \mathrm{~mm}$. Sin embargo, no se observó la presencia de defectos de contracción en ninguna de estas piezas. Se han publicado trabajos que estudian la aparición de rechupes y/o microrrechupes en piezas de fundición esferoidal fabricadas en moldes metálicos ${ }^{[21]}$. En el presente estudio, únicamente se ha detectado este tipo de defectos cuando se trabaja bajo dos condicionantes: carbonos equivalentes inferiores a 4,3 - 4,4\% y temperaturas del molde superiores a $250-260{ }^{\circ} \mathrm{C}$. La figura 5 muestra un ejemplo de la influencia de este segundo condicionante.

La superficie exterior de una pieza-testigo fabricada cuando las temperaturas medidas en el molde son elevadas $\left(265-295^{\circ} \mathrm{C}\right)$ muestra los surcos provocados como consecuencia de la contracción del material desde el interior de la pieza hacia las áreas de periferia en contacto con el molde (Fig. 5 (a)). Al reducir este parámetro crítico $\left(180-220^{\circ} \mathrm{C}\right)$, manteniendo similares el resto de condiciones, las piezas fabricadas están exentas de defectos de contracción internos y/o superficiales (Fig. 5 (b)).

Tras el desmoldeo y posterior enfriamiento hasta alcanzar la temperatura ambiente, las piezas fabricadas empleando los moldes permanentes muestran una superficie de aspecto metálico y recubierta por una fina capa de óxidos de hierro. Esta capa puede eliminarse fácilmente con un corto período de granallado. Comparativamente, el acabado superficial y la precisión dimensional de las piezas fabricadas con moldes metálicos (Fig. 6 (a)) son mejores y más repetitivos que los obtenidos cuando se utilizan los moldes de arena (Fig. 6 (b)).

Otro aspecto superficial a tener en cuenta es la presencia de reacciones molde-metal en las zonas de periferia pertenecientes a las piezas fabricadas con moldes de uno u otro tipo. Al utilizar moldes metálicos

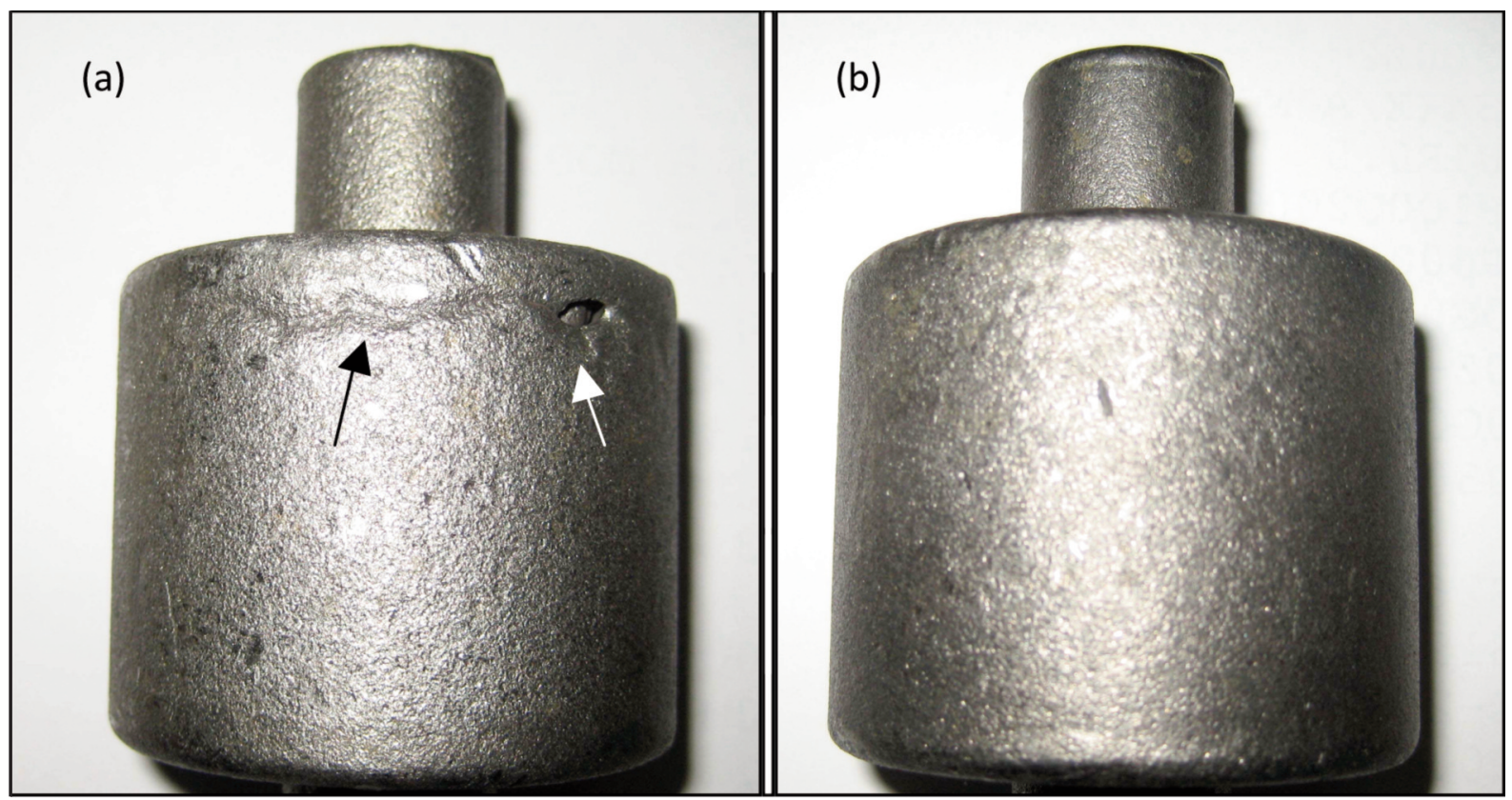

Figura 5. Estado superficial de una pieza fabricada en un: (a) molde a temperatura elevada y (b) molde a temperatura adecuada.

Figure 5. Surface quality in castings fabricated when the temperature of the metallic mould was: (a) too elevated and (b) appropriate. 
(Figs. 7 (a) y 7 (b)), no se detectan descarburaciones y/o la presencia de óxidos de hierro que sí están presentes en determinadas áreas de las piezas fabricadas con los moldes de arena (Figs. 7 (c) y 7 (d)).

Los defectos macroscópicos que se pueden encontrar ocasionalmente en las piezas fabricadas con moldes metálicos son: escorias, porosidades de gas y pliegues superficiales. En los dos primeros casos, dada la rapidez con la que transcurre el período de solidificación, es muy importante garantizar la limpieza del metal de colada y la efectividad de los sistemas de llenado a la hora de evitar la entrada de las escorias en las cavidades del molde y permitir la evacuación del gas presente en su interior. Con respecto a los pliegues superficiales, se ha observado que la formación de éstos se favorece cuando se emplean tiempos de colada prolongados, elevadas temperaturas de los moldes metálicos (Fig. 5) y, principalmente, en aquellos casos donde la composición del metal de colada es hipoeutéctica. Este hecho permite vincular las causas de la formación de los pliegues con los fenómenos de contracción del metal durante su solidificación.

La tabla $\mathrm{V}$ muestra los valores de la carga máxima de rotura $(\mathrm{R})$, el límite elástico (LE) y el alargamiento (A) obtenidos a partir de los ensayos de tracción efectuados con el fin de determinar las propiedades mecánicas de las piezas estudiadas en este trabajo.

Al comparar las propiedades mecánicas de las pinzas de freno $G$ en estado bruto de colada, se observan mayores valores del alargamiento en los materiales colados en moldes metálicos. Este com- portamiento, junto con los valores más bajos del parámetro $\mathrm{R}$ y de dureza, se puede explicar por el mayor contenido de ferrita en las pinzas fabricadas empleando los moldes permanentes. A su vez, este hecho tiene su origen en el importante incremento del parámetro $\mathrm{N}$ como consecuencia de la mayor velocidad de solidificación de la aleación. Estas características estructurales dan lugar a materiales que superan los $500 \mathrm{MPa}$ de carga de rotura y alargamientos que pueden alcanzar el 20\%. De forma adicional, en estas piezas se obtienen límites elásticos elevados (alrededor de $400 \mathrm{MPa}$ ) y similares a los observados en aquellos materiales fabricados en los moldes de arena. Por tanto, empleando moldes metálicos es posible obtener fundiciones esferoidales con estructuras comparativamente más homogéneas y de menor dureza (ambas son ventajas frente a las operaciones de mecanizado), además de límites elásticos similares a las calidades de fundición obtenidas en los moldes convencionales de arena.

En el caso de la pinza de freno E, los ensayos de tracción y dureza únicamente se han podido realizar sobre probetas obtenidas a partir de la sección más gruesa de la pieza $(43 \mathrm{~mm})$. Los resultados incluidos en la tabla $\mathrm{V}$ indican que las pinzas fabricadas con moldes metálicos y de arena muestran valores similares de $\mathrm{R}$ y de dureza (materiales en bruto de colada). Sin embargo, la utilización de las coquillas origina materiales con mayor LE y menores alargamientos. Estos resultados pueden relacionarse con la compo-

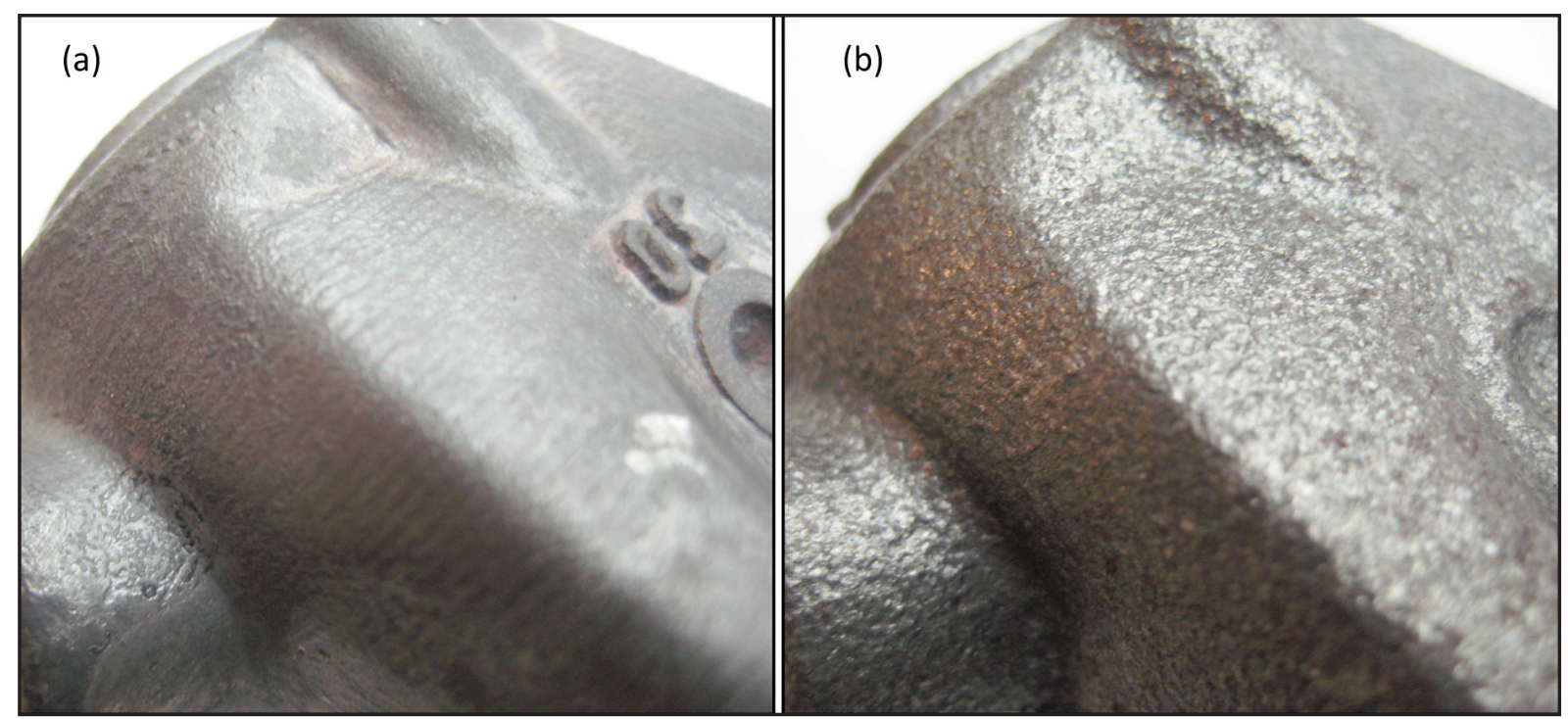

Figura 6. Calidad superficial en las piezas fabricadas utilizando moldes: (a) metálicos y (b) de arena.

\footnotetext{
Figure 6. Surface finish in castings produced using: (a) permanent moulds and (b) green sand moulds.
} 
Tabla V. Propiedades mecánicas y dureza Brinell obtenidas sobre pieza

Table V. Mechanical properties and Brinell hardness values obtained on castings

Pinzas de freno $\mathrm{G}$ en bruto de colada (molde metálico)

\begin{tabular}{cccccc}
\hline Sección $(\mathbf{m m})$ & Diámetro probeta $(\mathbf{m m})$ & $\mathbf{R}^{*}(\mathbf{M P a})$ & $\mathbf{L E}^{*}(\mathbf{M P a})$ & $\mathbf{A}^{*}(\%)$ & HBW \\
\hline $41-43$ & 10 & $505-520$ & $376-402$ & $16-20$ & $180-185$ \\
11 & 7 & $503-532$ & $380-414$ & $15-18$ & ---
\end{tabular}

Pinzas de freno $\mathrm{G}$ en bruto de colada (molde de arena de sílice)

\begin{tabular}{cccccc}
\hline Sección $(\mathbf{m m})$ & Diámetro probeta $(\mathbf{m m})$ & $\mathbf{R}^{*}(\mathbf{M P a})$ & LE $^{*}(\mathbf{M P a})$ & $\mathbf{A}^{*}(\%)$ & HBW \\
\hline $41-43$ & 10 & $605-706$ & $367-411$ & $9-11$ & $200-205$ \\
11 & 7 & $628-718$ & $378-418$ & $6-9$ & ---
\end{tabular}

Pinzas de freno E en bruto de colada (molde metálico)

\begin{tabular}{cccccc}
\hline Sección $(\mathrm{mm})$ & Diámetro probeta $(\mathrm{mm})$ & $\mathbf{R}^{*}(\mathrm{MPa})$ & LE $^{*}(\mathrm{MPa})$ & $\mathbf{A}^{*}(\%)$ & HBW \\
\hline 43 & 6 & $774-806$ & $473-554$ & $4-7$ & $230-245$
\end{tabular}

Pinzas de freno E en bruto de colada (molde de arena de sílice)

\begin{tabular}{cccccc}
\hline Sección $(\mathrm{mm})$ & Diámetro probeta $(\mathrm{mm})$ & $\mathbf{R}^{*}(\mathrm{MPa})$ & LE $^{*}(\mathrm{MPa})$ & $\mathbf{A}^{*}(\%)$ & HBW \\
\hline 43 & 6 & $769-793$ & $457-471$ & $8-9$ & $235-250$
\end{tabular}

Pinzas de freno $E$ tratadas térmicamente (molde metálico)

\begin{tabular}{cccccc}
\hline Sección $(\mathrm{mm})$ & Diámetro probeta $(\mathrm{mm})$ & $\mathbf{R}^{*}(\mathrm{MPa})$ & LE $^{*}(\mathrm{MPa})$ & $\mathbf{A}^{*}(\%)$ & HBW \\
\hline 43 & 6 & $507-538$ & $358-387$ & $18-22$ & $180-190$
\end{tabular}

\begin{tabular}{cccccc}
\hline \multicolumn{5}{c}{ Mordazas tratadas térmicamente (molde metálico) } \\
\hline Sección $(\mathbf{m m})$ & Diámetro probeta $(\mathbf{m m})$ & $\mathbf{R}^{*}(\mathrm{MPa})$ & LE $^{*}(\mathrm{MPa})$ & $\mathbf{A}^{*}(\%)$ & HBW \\
\hline 9 & 5 & $425-466$ & $294-313$ & $18-21$ & --- \\
7 & 5 & $435-469$ & $307-329$ & $17-19$ & -- \\
\hline
\end{tabular}

\footnotetext{
* El intervalo especificado incluye los valores obtenidos a partir de tres probetas mecanizadas a partir de tres
} piezas diferentes.

sición estructural en cada caso. Por un lado, los contenidos de ferrita/perlita son similares (secciones de $43 \mathrm{~mm}$ ) en las piezas fabricadas con ambos tipos de molde. Sin embargo, el valor del parámetro $\mathrm{N}$ es claramente mayor en las pinzas obtenidas utilizando los moldes metálicos, aspecto que podría estar relacio- nado con el aumento en los valores del LE pero no ser la causa de la reducción del alargamiento. Con el fin de justificar este último comportamiento, se realizaron análisis metalográficos en todas las superficies de rotura obtenidas tras los ensayos de tracción pertenecientes a las pinzas fabricadas en coquilla, sin 

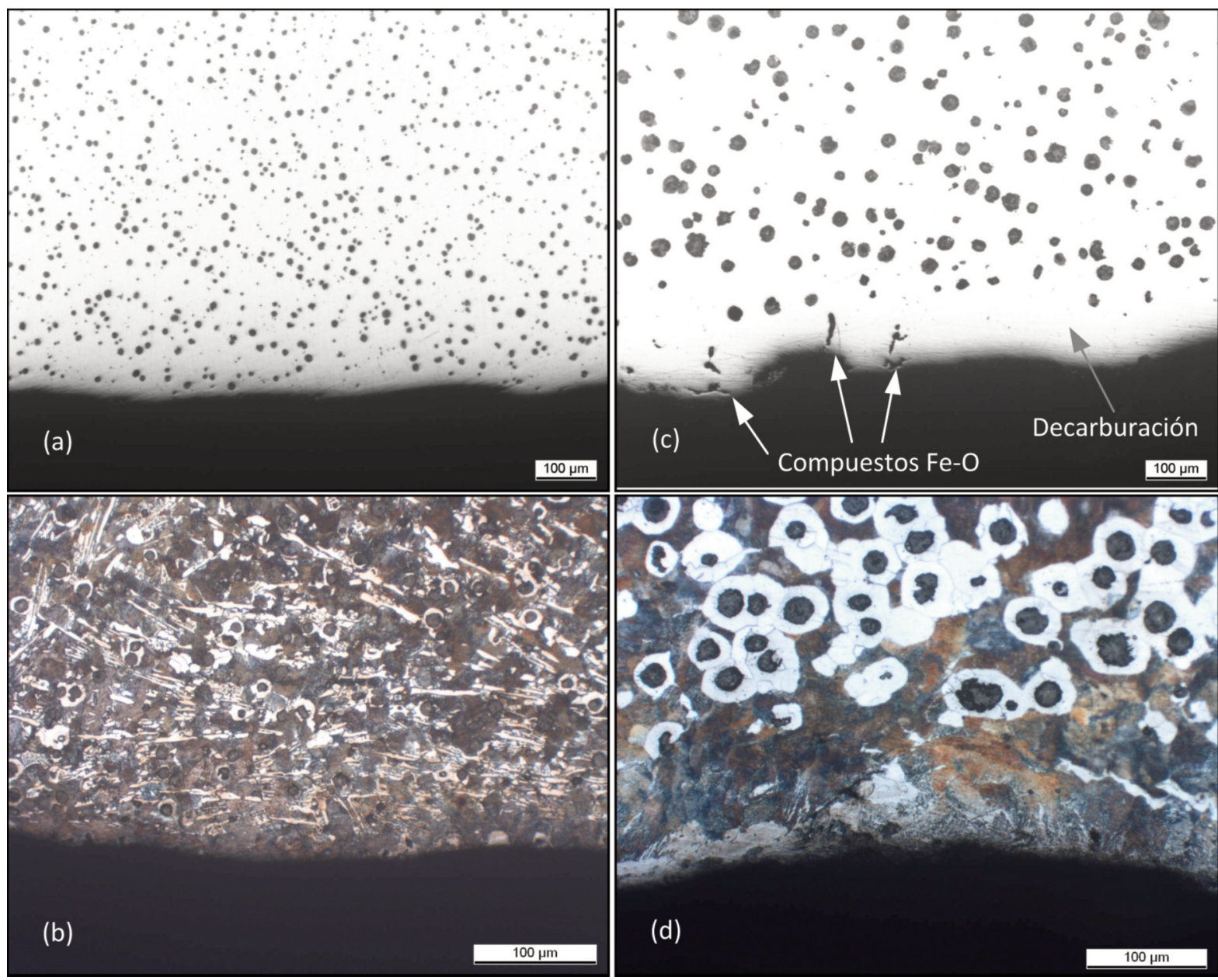

Figura 7. Detalle de la estructura en las secciones de $43 \mathrm{~mm}$ (zona de periferia) pertenecientes a la pinza E y fabricada en molde: (a) y (b) metálico; (c) y (d) de arena.

Figure 7. Details of the outer structure found in areas with $43 \mathrm{~mm}$ in section belonging to the callipers type E produced using: (a) and (b) a permanent mould; (c) and (d) a green sand mould.

que se detectara la presencia de carburos u otro tipo de defecto en ellas.

Tras aplicar el tratamiento térmico sobre las pinzas de freno E, las propiedades mecánicas obtenidas se asemejan a las descritas para las pinzas de freno $G$ con estructuras mayoritariamente ferríticas en el estado bruto de colada (Tabla V). En el caso de la mordaza de sujeción, el tratamiento térmico aplicado transformó la estructura ferritizándola completamente (ausencia de perlita). Como consecuencia, se obtienen cargas de rotura inferiores a $470 \mathrm{MPa}$, límites elásticos en torno a 300 - $330 \mathrm{MPa}$ y valores del alargamiento que pueden alcanzar el $21 \%$.

Aunque no se han descrito problemas en los ensayos de maquinabilidad realizados sobre todas las pinzas $G$, cualquiera que sea el tipo de molde utilizado para fabricarlas, sí se han detectado diferencias en la vida útil de la herramienta empleada para efectuar el mecanizado. Las piezas fabricadas con los moldes metálicos dieron lugar a un 20 - 30\% menos de desgaste en el proceso de desbastado del material metálico. Este comportamiento más favorable debe estar relacionado con los mayores valores del parámetro N (el grafito actúa como lubricante en el mecanizado) y el mayor contenido de ferrita (menor dureza) detectado en estas piezas con respecto a aquéllas fabricadas empleando los moldes de arena (Tabla IV).

El ensayo de corrosión mostró que, tras permanecer $792 \mathrm{~h}$ en el interior de la cámara de niebla salina, las pinzas E obtenidas a partir de los moldes de arena presentan importantes cantidades de óxido blanco en las superficies más externas y óxidos de hierro (color oscuro) en las zonas menos expuestas (Fig. 8 (a)).

En el caso de las pinzas E fabricadas utilizando la coquilla metálica, la cantidad de óxidos blancos es significativamente inferior y no se detecta la pre- 
sencia de óxidos de hierro (Fig. 8 (b)). En este punto, es necesario destacar que la zona donde aparecen los óxidos de color oscuro corresponde a un ángulo interno de la pieza, en el cual el acabado superficial es deficiente en las piezas fabricadas en los moldes de arena. En el caso de las pinzas E procedentes del molde metálico, esta zona muestra un acabado superficial destacable y similar al resto de las áreas que componen las piezas. La obtención de mejores acabados superficiales también influye en la efectividad del proceso de cromado de las piezas, disminuyendo los defectos asociados a la aplicación de este recubrimiento.

\section{CARACTERÍSTICAS DEL PROCESO UTILIZANDO MOLDES METÁLICOS}

A continuación se resumen las principales ventajas e inconvenientes encontrados en el proceso de fabricación cuando se utilizan moldes metálicos respecto a aquéllos preparados con mezclas de arena:

\section{Ventajas:}

- Mejor acabado superficial y mínima interacción molde-metal. Mayor facilidad en el proceso de limpieza superficial de las piezas fabricadas.

- La calidad superficial obtenida optimiza la efectividad de la aplicación de recubrimientos superfi- ciales en las piezas (por ejemplo el galvanizado) y disminuye la velocidad de corrosión del material.

- Facilidad en las operaciones de moldeo, desmoldeo y extracción de las piezas (sólo es necesario abrir y cerrar los moldes, además de efectuar su adecuado mantenimiento).

- Ausencia de inclusiones de arena (el defecto más común en las fundiciones que usan moldes de arena).

- Elevada densidad de esferoides por unidad de volumen de material (mayor homogeneidad en las propiedades del material).

- Debido a la mayor velocidad de solidificación, son necesarias menores adiciones de $\mathrm{FeSiMg}$ en los tratamientos para garantizar un correcto índice de esferoidización en el material.

- Bajo riesgo de contracción metálica para condiciones adecuadas de proceso (minimización de rechupes y microrrechupes). Es posible trabajar incluso sin sistemas de alimentación.

- Mayor posibilidad de obtener altos rendimientos en los moldes (relación entre el metal de las piezas y el metal total colado en el molde).

- Apenas existe el riesgo de deformaciones en los moldes por efecto de la presión dinámica y/o metalostática (mayores precisiones dimensionales en las piezas).

- Si existe un buen ajuste de los moldes, es sencillo eliminar las operaciones de acabado en las piezas (eliminación de rebabas).

- Un elevado número de esferoides por unidad de volumen se traduce en un aumento en la conductividad térmica del material y una mejora en su maquinabilidad.

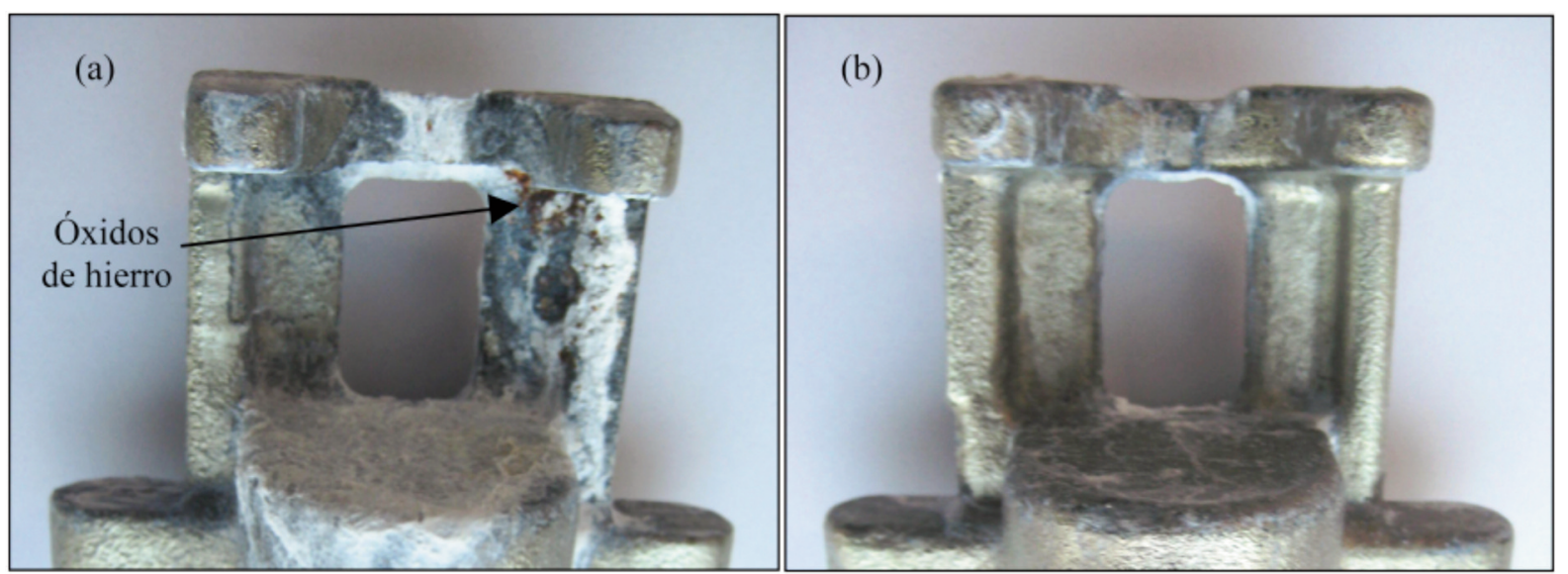

Figura 8. Óxidos depositados en la superficie de las pinzas $\mathrm{E}$ tras $792 \mathrm{~h}$ en el interior de la cámara de niebla salina: (a) pieza fabricada en molde de arena y (b) pieza fabricada en molde metálico.

Figure 8. Oxide products deposited on surfaces of the callipers type $E$ after $792 \mathrm{~h}$ inside the salt mine chamber: (a) casting produced using a green sand mould and (b) casting produced using a permanent mould. 


\section{Inconvenientes:}

- Mayor riesgo de formación de carburos en las zonas en contacto con el molde metálico y/o debido a fallos en el proceso de inoculación del metal. En tal caso, las piezas deben ser sometidas a tratamiento térmico.

- Las piezas tienen un mayor riesgo de mostrar defectos superficiales en forma de pliegues.

- Dificultades para la evacuación de gases (la permeabilidad de los moldes es nula).

- La fabricación de los moldes metálicos es comparativamente cara. Este hecho puede ser más acusado si la vida funcional del molde es baja.

- Es necesario contar con un sistema eficaz que permita controlar y regular continuamente la temperatura de los moldes metálicos durante el proceso de fabricación.

- La velocidad de producción de moldes colados puede ser menor que en un sistema de moldeo de alta presión con arena. Este hecho no supone un inconveniente en series cortas de producción.

\section{CONCLUSIONES}

- Los resultados obtenidos en el presente trabajo han demostrado que la utilización de moldes metálicos es una metodología efectiva y alternativa para la fabricación de piezas de fundición esferoidal con importantes requerimientos funcionales.

- La principal implicación estructural derivada del empleo de este tipo de moldes es el importante incremento en el número de nódulos grafíticos por unidad de volumen de material. Este hecho favorece la difusión del carbono disuelto en la fase Fe- $\gamma$ hacia los nódulos y, consecuentemente, aumentan los contenidos de ferrita en la matriz metálica una vez finalizada la transición eutectoide. Sin embargo, es necesario controlar adecuadamente la velocidad de enfriamiento de la fase austenítica tras el desmoldeo de las piezas con el fin de obtener la estructura matricial deseada en cada caso. De este modo, las características estructurales alcanzadas permiten fabricar piezas con propiedades mecánicas interesantes, destacando los elevados valores del límite elástico y alargamiento obtenidos en aleaciones con estructuras mayoritariamente ferríticas y exentas de carburos (bien sea en el estado bruto de colada o tratadas térmicamente).

- En el caso de que la matriz esté mayoritariamente constituida por perlita, se han obtenido materiales con valores destacables de $\mathrm{R}$ y LE y notables alargamientos. Otro aspecto a enfatizar es la mejor calidad superficial de las piezas fabricadas en moldes metálicos.

- En este tipo de metodología, se minimizan las reacciones molde-metal, evitando así la aparición local de inclusiones y/o degeneraciones grafíticas y mejorando significativamente la resistencia del material frente a los fenómenos de corrosión.

- Los requerimientos industriales derivados del proceso de producción utilizando moldes metálicos y los resultados presentados en este trabajo muestran la validez y factibilidad de esta metodología a la hora de fabricar piezas de fundición esferoidal con importantes requerimientos estructurales y mecánicos. De este modo, los fundidores y/o consumidores de fundición de hierro pueden contar con esta alternativa a la hora de definir cuál es la metodología más apropiada y rentable para la producción de las piezas demandadas.

\section{Agradecimientos}

Los autores agradecen la ayuda prestada en la ejecución de las pruebas experimentales al personal de Fundiciones Greyco, S.L.U., a los técnicos de Frenos Iruña, S.A.L. y a los responsables de TQC Technologies, S.L.U. Este trabajo está financiado por el Centro para el Desarrollo Tecnológico Industrial (CDTI) del Gobierno de España (ref. IDI 20101729).

\section{REFERENCIAS}

[1] J. Serrallach, J. Lacaze, J. Sertucha, R. Suárez y A. Monzón, Key Eng. Mat. 457 (2011) 361-366.

[2] J. Sertucha, J. Lacaze, J. Serrallach, R. Suárez y F. Osuna, Mater. Sci. Technol. 28 (2012) 184-191.

[3] J. Lacaze, P. Larrañaga, I. Asenjo, R. Suárez y J. Sertucha, Mater. Sci. Technol. 28 (2012) 603-608.

[4] M. Wessén y I. Svensson, Metall. Mater. Trans. A 27 (1996) 2.209-2.220.

[5] J. Sertucha, R. Suárez, J. Izaga, L.A. Hurtado y J. Legazpi, Int. J. Cast Metal. Res. 19 (2006) 315-322.

[6] G.M. Goodrich y R.W. Lobenhofer, AFS Trans. 115 (2007) trabajo 07-045.

[7] L.E. Björkegren y K. Hamberg, Keith Millis Symposium on Ductile Cast Iron, Ed. American Foundry Society, EE.UU., 2003, p. 21.

[8] I. Riposan, M. Chisamera y S. Stan, Int. J. Cast Metal. Res. 20 (2007) 64-67.

[9] B.V. Kovacs, AFS Trans. 89 (1981) 79-96.

[10] E.N. Pan, M.S. Lou y C.R. Loper, AFS Trans. 95 (1987) 819-840. 
[11] J. Sertucha, P. Larrañaga, J. Lacaze y M. Insausti, Int. J. Metalcast. 4 (2010) 51-58.

[12] J. Sertucha y R. Suárez, Arenas de moldeo en verde, $2^{\text {nd }}$ Ed.; Azterlan, Durango, 2005.

[13] M. Caldera, J.M. Borrajo, M.F. Rojas y B. Boeri, Proc. IV Coloquio Latinoamericano de Fractura y Fatiga, Argentina, 2000, pp. 139-146.

[14] A. Sedzimir, S. Parent-Simonin y J. Parisien, Fonderie 357 (1976) 217-233.

[15] Y.S. Lerner, Foundry Trade Journal, May (1999) 26-30.

[16] M.S.C. Rao y M.N. Srinivasan, AFS Trans. 96 (1988) 551-554.
[17] P. Schmidt, J. Bast, M. Aitsuradze y L. Arnberg, Int. J. Cast Metal. Res. 23 (2010) 1-6.

[18] E.F. Ryntz, Jr., AFS Trans. 84 (1976) 551-554.

[19] Reference microstructure for measurement of pearlite and ferrite content in ductile iron microstructures, AFS current information report, Quality Control Committee 12-E, Ductile Iron Division, 1984.

[20] R. Suárez, J.M. Gutiérrez, A. Loizaga, P. Larrañaga y J. Sertucha, Rev. Metal. 45 (2009) 339-350.

[21] M.S.C. Rao y M.N. Srinivasan, AFS Trans. 96 (1988) 599-602. 